\title{
Loss of vision in a bleeding peptic ulcer patient following resuscitation - an unusual cause of non-arteritic anterior ischaemic optic neuropathy

\author{
MSH MAJUMDER
}

\begin{abstract}
Summary:
A 55-year old male, known to have peptic ulcer disease for 4 years, started haematamesis and melaena in a rural area of Bangladesh and was admitted into hospital with circulatory collapse. He was resuscitated with 8 units of whole blood transfusion and became stable. But he
\end{abstract}

\section{Introduction:}

Peptic ulcer disease is very common in our population and with the availability of newer H2blockers, proton pump inhibitors and antihelicobacter pylori regimens, the complications of peptic ulcer disease, like bleeding, perforation, obstruction etc. have not been reduced that much significantly. The important and fatal complication of peptic ulcer disease is bleeding from ulcer site. Bulk majority of upper gastrointestinal bleeding constitutes bleeding from peptic ulcer site and may bring to mortality if not managed properly. Severe bleeding leads to haemorrhagic shock and multiorgan failure, endangering the life ${ }^{1-4}$. Loss of vision which can be unilateral or bilateral, transient or persistent; is a very rare consequence of severe bleeding. Severe haemorrhage can cause sudden bilateral loss of vision by ischaemia of optic nerve head called anterior ischaemic optic neuropathy. Anterior ischaemic optic neuropathy is classified as arteritic and non-arteritic form. Giant cell arteritis is considered as an important cause of arteritic form of anterior ischaemic optic neuropathy. Non-arteritic anterior ischaemic optic neuropathy is a partial or total infarction of the optic nerve head caused by occlusion of the short posterior ciliary arteries; leads to optic disc swelling and loss of vision ${ }^{5-9}$.

Address for correspondence: Dr. Md. Shafayet Hasan Majumder, Assistant Professor of Medicine, Medical College for Women and Hospital, Uttara Model Town, Dhaka-1213

Received: 17 December, 2006

Accepted: 21 April, 2007 developed sudden loss of vision and fundoscopy revealed bilateral papilloedema but CT scan appeared normal. Clinical and ophthalmological evaluation was consistent with non-arteritic anterior ischaemic optic neuropathy. Key words : optic neuropathy ; peptic ulcer

(J Bangladesh Coll Phys Surg 2008; 26: 50-54)

\section{Case report:}

A 55-year old non-diabetic, normotensive, exsmoker, known peptic ulcer disease for four years, started upper gastrointestinal bleeding, manifested as haematamesis and melaena in a rural area of Bangladesh. He was brought to hospital in a collapsed state - altered mental state, low volume rapid pulse, low blood pressure and urine volume supression. $\mathrm{He}$ was managed by oxygen inhalation, intravenous fluids and blood transfusion after blood grouping and cross matching, intravenous ranitidine and dopamine infusion. His haematamesis and melaena continued for four days and blood was also transfused simultaneously, a total of eight units of human whole blood. His $\mathrm{Hb}$ fell to $4 \mathrm{~g} / \mathrm{dl}$, slight increase in urea, normal serum electrolytes, normal blood sugar and liver function tests. After settling general condition, he was undergone upper gastrointestinal endoscopy, revealing no oesophageal or gastric varices but gastric ulcer with evidence of recent bleeding and deformed duodenal bulb ( Fig. 1). The patient became stable and about to discharge the next day but unfortunately, he developed bilateral loss of vision. His wife was saying that, on awakening at morning, her husband asked her, why night was so long. She surprised, saying that it was not night but morning and came to know that he could not see anything because of loss of vision. Fundoscopy revealed bilateral papilloedema with retinal haemorrages ; and central white spots called Roth's spots (Fig. - 2). A CT scan of brain was advised immediately which revealed neither intracranial space occupying lesions nor abnormality of ventricular system (Fig. - 3). So, 
local causes of optic disc swelling were thoroughly searched, like optic neuritis, central retinal vein occlusion, optic nerve tumour, lymphoma or leukaemic infiltration etc; and his both orbital cavities on CT scan did not show optic nerve tumour, orbital tumors or any other retro-orbital masses (Fig. - 4). He was having no clinical features suggestive of giant cell arteritis or other collagen vascular diseases. A diagnosis consistent with non-arteritic anterior ischaemic optic neuropathy was made. Fluorescent angiography was advised but regreted because of financial constrains. His visual acuity showed no perception of light. He was given antiulcer drugs, antihelicobacter pylori regimens, methycobalamine, vitamin B complexes; and advised follow up visit for fundoscopy. Fundoscopy after one month showed bilateral secondary optic atrophy with vascular sheathing and absorption of retinal haemorrhages ( Fig.-5 ); and visual acuity still showed no perception of light. The next follow up visit - 5 months after becoming blind; showed improvement of vision with perception of movement of objects.

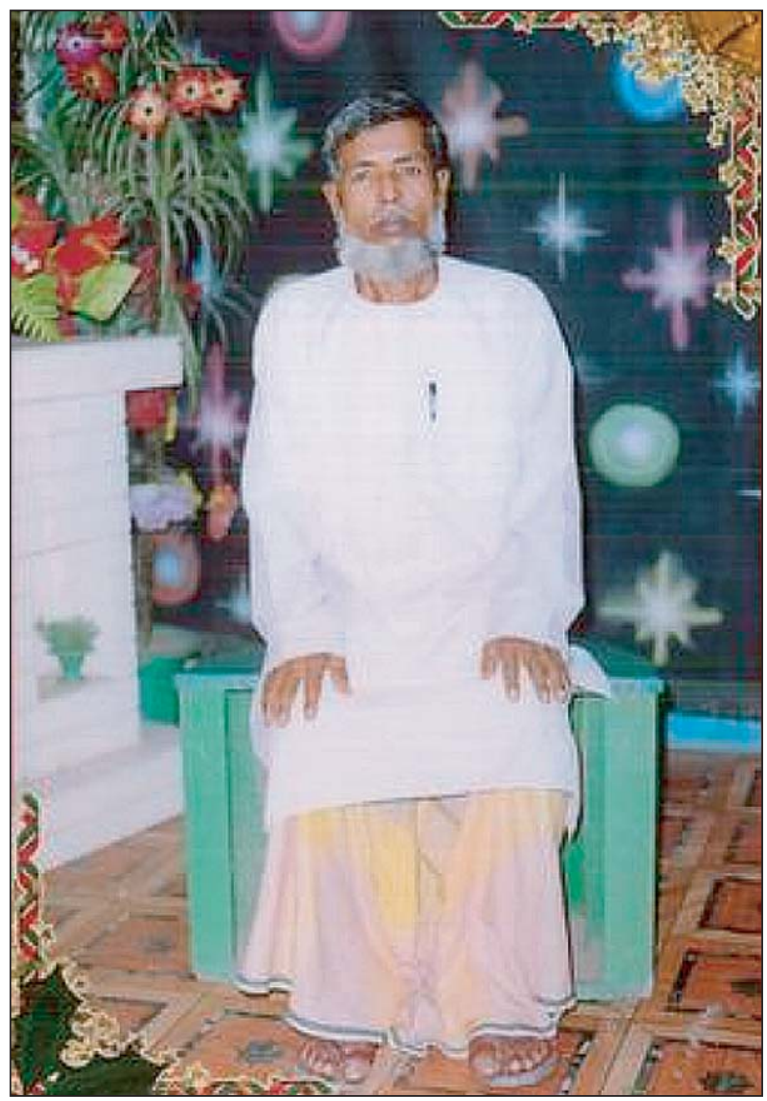

Photograph of the patient

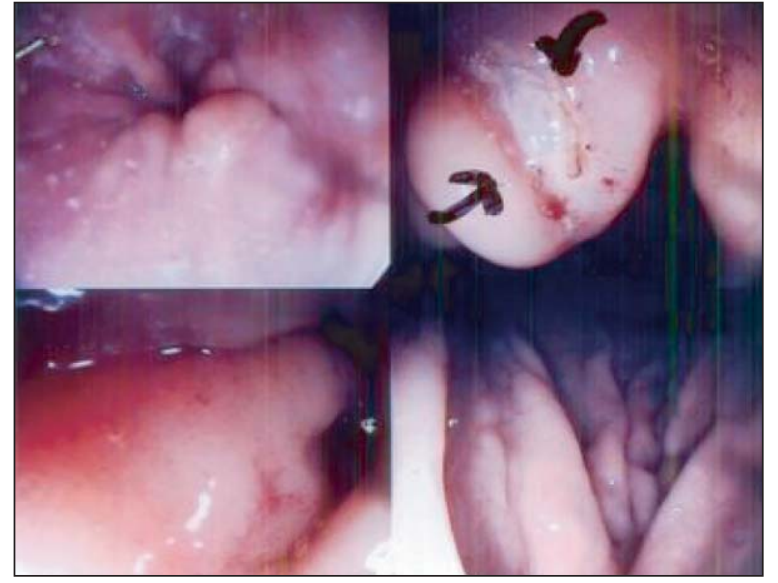

Fig.-1: Upper G I Endoscopy showing gastric ulcer with evidence of recent bleeding and deformed duodenal bulb.

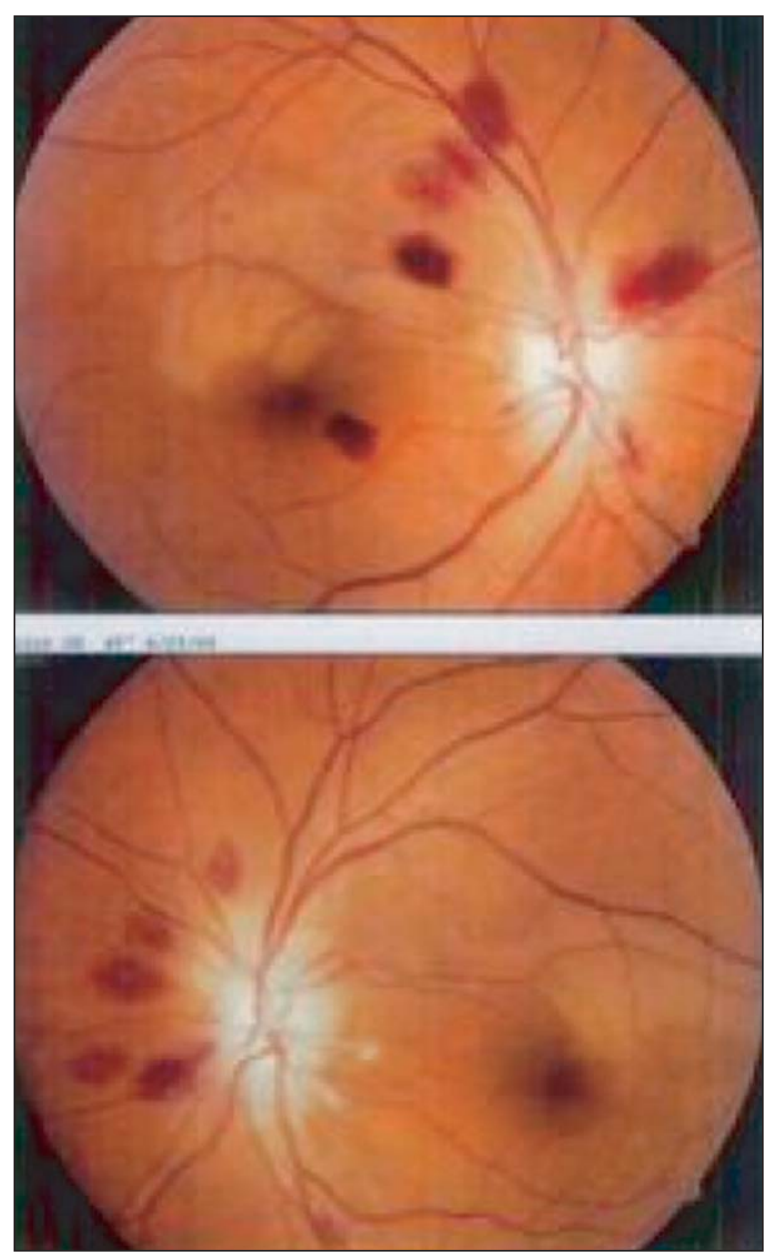

Fig.-2: Bilateral papilloedema with retinal haemorrages 


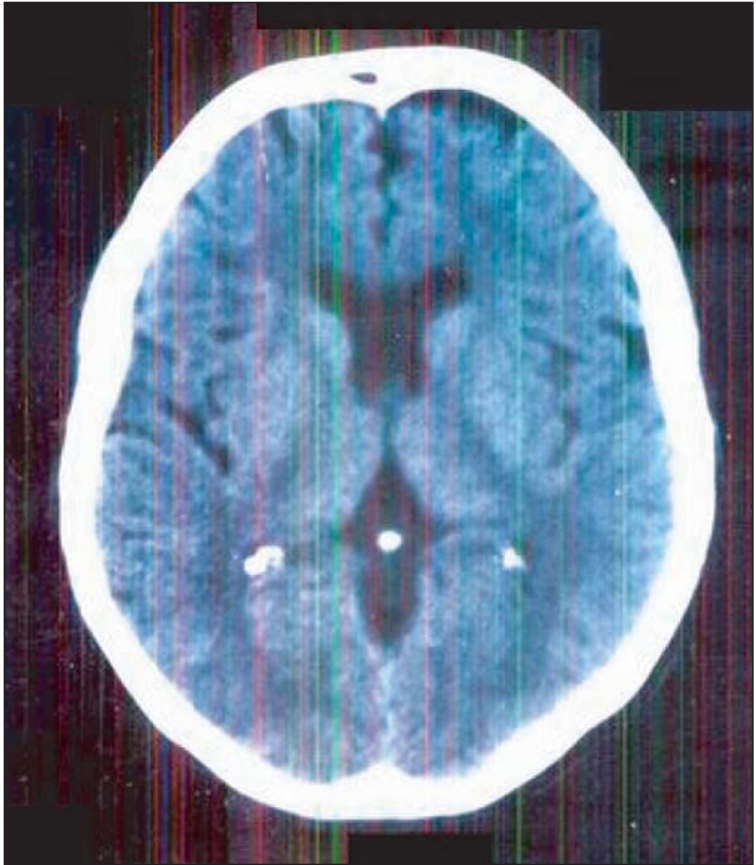

Fig.-3: CT Scan of brain showing no intracranial space occupying lesions.

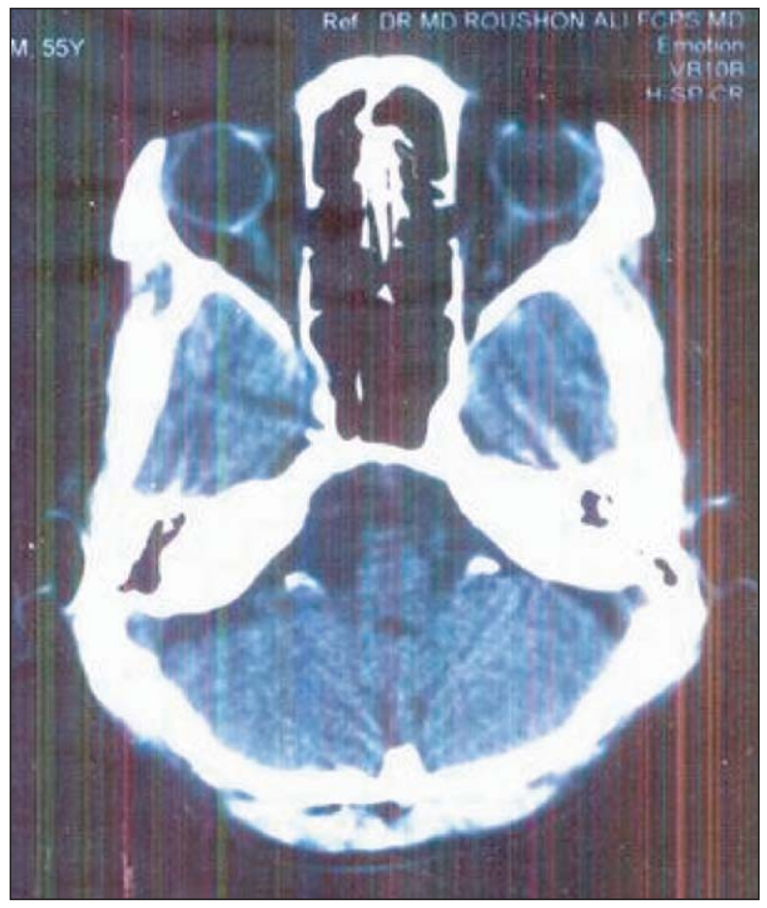

Fig.-4: Normal orbit and retro-orbital structure
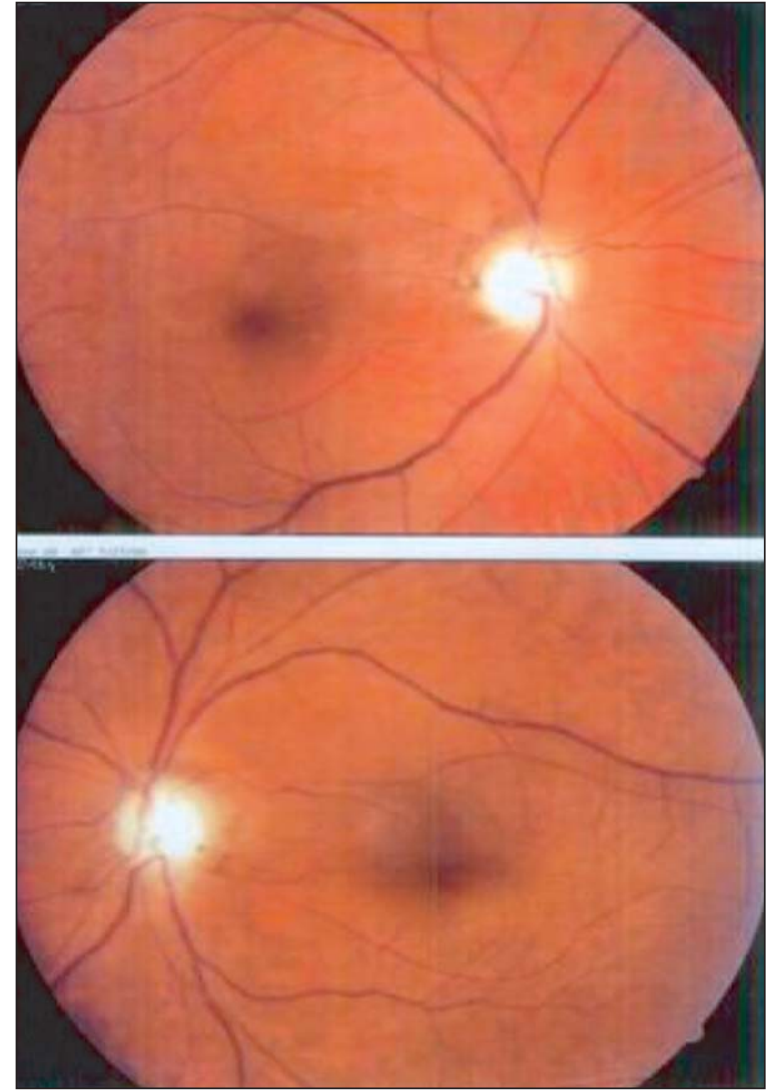

Fig.-5: Bilateral secondary optic atrophy

\section{Discussion:}

Bleeding peptic ulcer disease is a medical emergency and we usually concentrate to resuscitate the patient with blood transfusion, and also to find out the cause. We rarely consider blindness as a complication of bleeding peptic ulcer disease. In this patient, immediate fundoscopy following loss of vision showed bilateral optic disc swelling or papilloedema. Optic disc or optic nerve head swelling may be caused by a variety of conditions that are conviniently classified into papilloedema, pseudopapilloedema, and local causes. The clinician must be able to differentiate whether the swelling indicates serious life or sight threatening pathology, or is a coincidental finding of little significance. Papilloedema refers to optic disc swelling caused by raised intracranial pressure. Pseudopapilloedema refers to those benign conditions that resemble papilloedema either by the manner of presentation, or by the disc appearance, 
causes include optic disc drusens or anomalous disc. Local causes of optic disc swelling include a variety of conditions for which careful examination of visual fields, fundus, vitrous and orbit usually provides a diagnosis. The two most common, anterior ischaemic optic neuropathy and demylinating optic neuritis, present with characteristics symptoms and signs ${ }^{8-13}$.

Anterior ischaemic optic neuropathy refers to optic disc swelling and loss of vision caused by ischaemia in the territory of the short posterior ciliary arteries and subdivision into a non-arteritic form and an arteritic form serves a useful clinical functions. The arteritic form of AION (Anterior Ischaemic Optic Neuropathy) is mostly due to giant cell arteritis which can be diagnosed by characteristic features of headache, jaw pain and scalp tenderness over temporal artery region; high ESR and C-reactive protein; and characteristic temporal artery biopsy ${ }^{8,9}$.

Non-arteritic anterior ischaemic optic neuropathy is a partial or total infarction of the optic nerve head, also caused by occlusion of the short posterior ciliary arteries, typically occurs between ages of 45 and 65 years with structural crowding of optic nerve head. Predisposing systemic conditions include smoking, hypertension, diabetis mellitus, hypercholesterolaemia, collagen vascular disease, hypotensive events and cataract surgery ${ }^{8-10}$. Presentation is with sudden, painless unilateral visual loss which is frequently discovered on awakening, suggesting that nocturnal hypotension may play an important role. Simultaneous bilateral non-arteritic ischaemic optic neuropathy is very rare, but may follow major haemorrhage. In the reported case, this was due to major haemorrhage or may be due to sustained hypotension. Major haemorrhage, whatever may be the cause, can lead to ischaemic optic neuropathy. Over a period of 6 months, 40 percent of affected eyes show a spontaneous improvement, whilst 20 percent deteriorate ${ }^{9}$. There is an increased incidence of cerebrovascular and cardiovascular disease. Decrease of blood pressure or arterial hypotension may be considered as a risk factor of non-arteritic anterior ischemic optic neuropathy ( NAION ), leading to a vascular insufficiency in the optic nerve head ${ }^{14-17}$.
This patient had sustained arterial hypotension while he was having bleeding for four days.

\section{Conclusion:}

Severe haemorrhage is always considered as a life threatening condition and we would like to emphasize that it is not only life threatening but can also be sight threatening, even if life could have been saved. So, correction of underlying cause and adequate measures can prevent or minimize loss of vision.

\section{Acknowledgement:}

My deepest gratitude and gratefulness are extended to the patient Mr. Chand Mia and all his family members for their help and co-operation.

\section{References:}

1. Palmer KR, Penmar ID, Paperson S. Alimentary tract and pancreatic disease. In: Haslett C, Chilver ER, Hunter JAA, Boon NA, editors. Davidson's principles \& practice of medicine. 19th ed. Edinberg : Churchill Livingstone; 2002. p. $764-6,782-8$.

2. Laine L. Gastrointestinal bleeding. In: Kasper DL, Fauci AS, Braunwald E,. Isselbacher KJ, Wilson JD, Martin JB, et al. editors. Harrison's principles of internal medicine. 16th ed. New York : McGraw-Hill Companies ; 2005. vol-1, p. 235-8.

3. McQuaid KR. Alimentary tract. In:Tierney LM, McPhee SJ, Papadakis MA, editors. Current medical diagnosis \& treatment. 44th ed. New York : Lange Medical Books / Mc Graw Hill ; 2005. p. 533-6.

4. Abraham Bogoch. Bleeding from alimentary tract. In: Haubrich WS, Schaffner F, editors. Bockus gastroenterology. 5th ed. Philadelphia : W.B. Saunders Company ; 1995. vol-1, p. 62-84.

5. Pounder RE, Eraser AG. Diagnosis, medical management and complications of peptic ulcer disease. In: Haubrich WS, Schaffner F, editors. Bockus gastroenterology. 5th ed. Philadelphia : W.B. Saunders Company ; 1995. vol-1, p. 770-77.

6. Longmore M, Wilkinson IB, Rajagopalan SR. Oxford hand book of clinical medicine. 6th ed. Oxford : Oxford University Press ;2004. p. 224-6, 804-5.

7. Cello JP. Gastrointestinal haemorrhage. In: WynGaarden JB, Smith LH, Bennett JC, editors. Ceceil text book of medicine.19th ed. Philadelphia : W. B. Saunders Company ; 1992. vol-1, p. 742-6.

8. Kanski JJ. Clinical ophthalmology. 5th ed. London : Butterworth Heinemann ; 2003. p. 603-6. 
9. Burdon MA, Saunder MD. Papilloedema, pseudopapilloedema and local causes of optic disc swelling. In: Easty DL, Sparrow JM, editors .Oxford text book of ophthalmology. Ist ed. 1999. vol-2 p. 830-7.

10. Anderson DR, Quigley HA. The optic nerve. In: Hart WM, editor. Adler's physiology of eye . 9th ed. Harcourt Brace \& Company ; 1992: p. 616-24.

11. Targownik LE, Nabalamba A. Trends in management and outcome of acute nonvariceal upper gastrointestinal bleeding ; 1993-2003. Clin Gastroenterol Hepatol 2006 ; 11 (10) : p. $16-9$.

12. Collins D, Worthley LI. Acute gastrointestinal bleeding : part 1. Crit Care Resusc 2001 ; 6 ; 3 (2) : p. 105-16.

13. Arber N, Tiomny E, Hallak A, Santo M, Moshkowitz M, Konikoff FM, et al. An eight year experience wih upper gastrointestinal bleeding : diagnosis, treatment and prognosis. J Med 1994 ; 25(5) : p. 261-9.

14. Bulboaca A, Nicula C. Arterial hypotension - risk factor in nonarteritic anterior ischemic optic neuropathy. Oftalmologia $2002 ; 53(2):$ p. $52-5$.

15. Tsai RK, Liu YT, Su MY. Risk factors of non-arteritic anterior ischemic optic neuropathy (NAION) : ocular or systemic. Kaohsiung J Med Sci 1998 ; 4 ; 14(4) : p. 221-5.

16. Sawle GV, James CB, Russell RW. The natural history of non-arteritic anterior ischemic optic neuropathy. J Neurol Neurosurg Psychiatry $1990 ; 10 ; 53(10)$ : p. 830-3.

17. Hayreh SS. Anterior ischemic optic neuropathy. Differentiation of arteritic from non-arteritic type and its management. Eye 1990 ; 4 (1) : p. 25-41. 